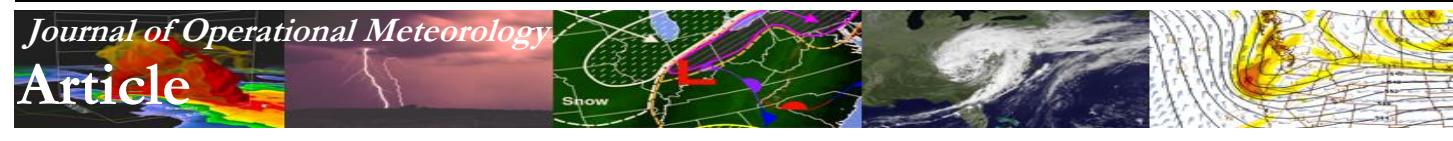

\title{
Evaluating ENTLN Performance Relative to TRMM/LIS
}

\author{
SCOTT D. RUDLOSKY \\ NOAA/NESDIS/STAR, College Park, Maryland
}

(Manuscript received 15 August 2014; review completed 12 December 2014)

\begin{abstract}
This study evaluates three years (2011-13) of data from the Earth Networks Total Lightning Network (ENTLN) relative to the Tropical Rainfall Measurement Mission (TRMM) Lightning Imaging Sensor (LIS). Within the Western Hemisphere $\left(38^{\circ} \mathrm{N}\right.$ to $\left.38^{\circ} \mathrm{S}\right)$, the relative flash detection efficiency (DE) increases from 21.6\% during 2011 to 31.4\% during 2013. Performance improves in each geographical subdomain, with the best regional performance $(71.9 \%)$ over the southern contiguous United States (south of $38^{\circ} \mathrm{N}$ ). The daily relative flash DE generally exceeds $15 \%(50 \%)$ in the Western Hemisphere (North America), but large dayto-day variability is evident. The average distance (timing) offset between matched LIS flashes and ENTLN events is $10.8 \mathrm{~km}(+25.0 \mathrm{~ms})$. Although the average timing offset is positive, the ENTLN reports its first event before $48.6 \%$ of LIS flashes begin. Multiple ENTLN events occur during most matched LIS flashes, and the ENTLN defines 51.3\% of all matched LIS flashes as cloud-to-ground (CG). National Lightning Detection Network data help characterize flash type [CG versus intra-cloud (IC)], allowing investigation of the LIS characteristics of IC and CG flashes. The ENTLN detects the most intense LIS flashes, and the LIS characteristics indicate that CG flashes transfer more charge than IC flashes. The maximum number of events per group and maximum group area are much larger for confirmed $C G$ flashes $\left(14.9\right.$ and $378.4 \mathbf{k m}^{2}$, respectively) than for confirmed IC flashes $\left(7.7\right.$ and $200.4 \mathrm{~km}^{2}$, respectively).
\end{abstract}

\section{Introduction}

Many meteorological applications use lightning observations from both ground- and space-based lightning detection systems. These systems detect optical or radiometric lightning signals, and their data are growing in importance to scientists and operational weather forecasters. Total lightning observations are useful for both storm warning and public safety applications. Rapid increases in total lightning flash rate often precede severe weather (Williams et al. 1999). This knowledge has been used to develop a lightning jump algorithm that provides early warning of severe weather events (Schultz et al. 2009, 2011; Gatlin and Goodman 2010). Lightning data also have been used to refine satellite precipitation estimates $(\mathrm{Xu}$ et al. 2013, 2014), improve hurricane intensity forecasts (DeMaria et al. 2012), and provide initial conditions for weather forecasting models (Fierro et al. 2012). Lightning observations have additional public safety applications related to airport operations, recreational activities, and sporting venues. As the number of networks and variety of users expand, it becomes increasingly important to understand the detection capabilities of these networks.

This study evaluates the detection efficiency (DE) of the Earth Networks Total Lightning Network (ENTLN) relative to total lightning observations from the satellite-based Tropical Rainfall Measuring Mission (TRMM) Lightning Imaging Sensor (LIS). Thompson et al. (2014) conducted an early evaluation of the ENTLN relative to the TRMM/LIS (1 January 2010 and 30 June 2011). Although differing methods, study periods, and subdomains limit direct comparisons with Thompson et al. (2014), the present study builds upon and generally supports their findings. The ENTLN performance is documented during 2011-13 to illustrate its variability in space and time. This study aims to improve our understanding of the ENTLN detection capabilities to better prepare scientists and forecasters to use these data for weather research and forecasting operations.

Corresponding author address: Scott D. Rudlosky, 5825 University Research Ct., Suite 4001, College Park, MD 20740

E-mail: scott.rudlosky@noaa.gov 


\section{Data and methods}

\section{a. Data}

Three years (2011-13) of ENTLN and LIS data are compared within the LIS field of view $\left(38^{\circ} \mathrm{N}\right.$ to $\left.38^{\circ} \mathrm{S}\right)$ in the Western Hemisphere $\left(0^{\circ}\right.$ to $\left.-180^{\circ} \mathrm{W}\right)$. Our domain was chosen to encompass the region of overlapping coverage between the LIS and the planned Geostationary Operational Environmental Satellite-R (GOES-R) Geostationary Lightning Mapper (GLM; Goodman et al. 2013). The ENTLN and LIS detect lightning differently. The ENTLN continuously detects electromagnetic pulses generated by lightning, whereas the low-earth orbiting LIS observes $\sim 90 \mathrm{sec}$ of optical emissions from lightning at each point within its moving field of view $(600 \mathrm{~km} \times 600 \mathrm{~km}$; Christian et al. 1999). This study compares ENTLN events [i.e., both intra-cloud (IC) and cloud-to-ground (CG)] with LIS flashes. Although the ENTLN combines events into flashes, we chose to use the ENTLN events rather than relying on the ENTLN flash grouping criteria $(10 \mathrm{~km}$ and $700 \mathrm{~ms}$; Liu and Heckman 2012). ENTLN events occur at discrete places and times (i.e., no duration or area), making them most similar to LIS groups. However, because LIS groups (i.e., clusters of illuminated pixels that last $\sim 2 \mathrm{~ms}$ ) are less intuitive than (visually distinguishable) flashes, and presently have no direct applications, LIS flashes were chosen as the basis for comparison. LIS flashes have durations of 10s to 100s of ms and spatial extents of $10 \mathrm{~s}$ to $100 \mathrm{~s}$ of $\mathrm{km}^{2}$.

The TRMM LIS was launched into low-earth orbit $(350 \mathrm{~km})$ during November 1997 (Christian et al. 1999), providing coverage between $38^{\circ} \mathrm{N}$ and $38^{\circ} \mathrm{S}$. The orbit was subsequently boosted to $\sim 400 \mathrm{~km}$ in 2001 to increase mission lifetime, with no impact on DE (Cecil et al. 2012). The LIS identifies lightning events by measuring optical pulses (integrated over a period of $\sim 2 \mathrm{~ms}$ ) associated with changes in cloud brightness within $\sim 5 \mathrm{~km} \times 5 \mathrm{~km}$ pixels (Christian et al. 1999; Mach et al. 2007). The LIS reports the time, location, and radiant energy of individual total lightning events (Christian et al. 1999). These events (single illuminated pixels) are combined into groups, flashes, and areas using optical pulse-to-flash and flash-to-cell clustering algorithms (Boccippio et al. 2002). Adjacent (i.e., with a side or corner touching), simultaneous events are combined to form groups. Groups are further combined into flashes using a weighted Euclidean distance method with spatial and temporal weighing constraints of $5.5 \mathrm{~km}$ and $330 \mathrm{~ms}$ (Mach et al. 2007).

The estimated LIS flash DE is $~ 90 \%$ at night and $\sim 70 \%$ at local noon (Boccippio et al. 2002; Cecil et al. 2012). LIS detection efficiency is directly related to the relative brightness of the lightning events, which varies based on the time of day and flash characteristics (e.g., IC/CG, current, and altitude). Although the LIS sees some flashes better than others, our analysis assumes that the LIS observes all lightning in its field of view. The intensity of LIS flashes (i.e., the amount of charge transferred) can be inferred from their radiance (brightness), duration, and area. Because IC and CG flashes emit similar optical pulses, both types are readily observed from above (Christian et al. 1992).

Much remains to be learned about the ENTLN dataset following its rapid expansion and operational implementation. The following description paraphrases Liu and Heckman (2012) to introduce the present state of knowledge on the ENTLN operations. The ENTLN monitors total lightning activity using wideband sensors with detection frequencies ranging from $1 \mathrm{~Hz}$ to $12 \mathrm{MHz}$. The wide frequency range enables the sensor to detect CG strokes, as well as the typically weaker IC pulses. The detection of IC pulses requires tradeoffs among sensor sensitivity, signal processing capability, and sensor baseline distances (Cummins and Murphy 2009). The ENTLN employs a blended technique to provide a degree of global coverage with better performance (i.e., total lightning detection) in regions with greater sensor density. Their expanding high-density network presently covers the contiguous United States (CONUS), Alaska, Hawaii, the Caribbean basin, Australia, Brazil, and Guinea. The ENTLN also began incorporating waveforms from the World-Wide Lightning Location Network (WWLLN) during December 2011 to improve longrange performance.

Lightning generates electromagnetic pulses that propagate as radio waves in all directions. Multiple ENTLN sensors detect and record these pulse waveforms, and transmit them to a central server for processing. As with many other time-of-arrival (TOA) lightning detection networks (e.g., WWLLN), the arrival times are calculated by correlating the waveforms from all sensors that detect an event. Two characteristics that distinguish the ENTLN from other networks are its sensor technology (i.e., wide-frequency range) and proprietary systems for processing waveforms. The waveform arrival time, shape, and 
signal amplitude are used to determine the event type (IC or CG), polarity, peak current, and locationincluding latitude, longitude, and height (for IC events only; S. Heckman 2014, personal communication). Lightning events are classified as IC unless a CG return stroke signature is detected. The only ENTLN characteristics directly examined herein are the occurrence, location, and IC/CG classification.

Uncertainties remain regarding the classification of lightning events as IC or CG. Mallick et al. (2013, 2014) showed a tendency for the ENTLN to misclassify subsequent (weak) CG return strokes as IC flashes. Because the LIS characteristics of IC and CG flashes are of interest, data from the National Lightning Detection Network (NLDN) are incorporated to better characterize flash type (IC versus CG). The NLDN detects $90-95 \%$ of all CG flashes (Cummins and Murphy 2009), but also misclassifies some IC discharges as low-amplitude $+\mathrm{CG}$ reports (Cummins et al. 1998; opposite the ENTLN misclassification noted above). Most NLDN reports between 0 and $10 \mathrm{kA}$ are IC discharges; most above $20 \mathrm{kA}$ are $\mathrm{CG}$ discharges; but those between 10 and $20 \mathrm{kA}$ are a mixture of CG and IC discharges (Cummins et al. 2006). Biagi et al. (2007) suggested removing weak +CG reports with estimated peak currents $<15 \mathrm{kA}$, because between 15 and $20 \mathrm{kA}$ the number of correct (CG) reports equals the number of false (IC) reports. The present study chose to retain the weak +CG NLDN reports because their relation to the LIS and ENTLN is of interest. The ENTLN will report events as weak as $1 \mathrm{kA}$, and no minimum estimated peak current threshold is employed. Unlike LIS flashes, ENTLN events have no duration or size, and their strength is inferred from their estimated peak current.

Both the LIS and ENTLN exhibit diurnal DE variability that the present study does not address. TRMM has a low-altitude, low-inclination orbit that precesses through the local diurnal cycle (Simpson et al. 1988), reducing the impact of diurnal DE variability on the lightning distributions. The LIS only samples a given point while directly overhead, which is approximately $0.1 \%$ of the time in the tropics $\left(\sim 876 \mathrm{~h} \mathrm{yr}^{-1}\right)$. However, the precessing orbit makes this overpass frequency sufficient to produce accurate annual climatologies (e.g., Christian et al. 1999, 2003) and to evaluate ground-based lightning detection networks (e.g., Rudlosky and Shea 2013; Thompson et al. 2014).

\section{b. Methods}

This study matches individual LIS flashes and ENTLN events to accurately determine the relative ENTLN flash DE. Direct flash-to-event comparisons also reveal the location and timing differences (offsets) between matched flashes, the number of ENTLN events associated with each matched LIS flash, and the LIS characteristics (e.g., duration and area) of matched, unmatched, CG, and IC flashes.

Individual LIS flashes are matched with ENTLN events using the methods described by Rudlosky and Shea (2013). Neither network detects all lightning, but the LIS provides the baseline for this analysis. Many time $(50 \mathrm{~ms}$ to $1 \mathrm{~s})$ and distance (1 to $100 \mathrm{~km})$ thresholds were examined to determine the best matching criteria. Very tight spatial $(1 \mathrm{~km})$ and temporal $(50$ $\mathrm{ms}$ ) thresholds reduce the relative DE by roughly half, but outside these tight criteria, reasonable changes to the matching thresholds produce very small differences ( $<5 \%$ change in DE depending on the sample). We selected distance $(25 \mathrm{~km})$ and time $(330 \mathrm{~ms})$ thresholds at the broad end of the spectrum to remain consistent with Rudlosky and Shea (2013) and to ensure identification of all matches both inside and outside the CONUS (i.e., areas of high and low sensor density). These somewhat liberal matching criteria are narrower than those used by Thompson et al. (2014; $400 \mathrm{~ms}$ and $0.15^{\circ}$ latitude/longitude), but still require caution to avoid double counting. Geographical Information System (GIS) software also was used to visualize portions of the datasets and ensure proper matching.

LIS flashes comprise multiple LIS groups whose times and locations are used to define the spatial and temporal extents of LIS flashes. For LIS flashes to be considered a match, an ENTLN event must occur within $25 \mathrm{~km}$ of any group in an LIS flash (i.e., furthest groups north, south, east, and west) and within $330 \mathrm{~ms}$ before, during, or after an LIS flash. Although LIS groups are used to define the beginning, end, and spatial extents of each LIS flash, we report only the fraction of LIS flashes detected by the ENTLN (i.e., not the fraction of LIS groups or LIS events). Multiple ENTLN events typically occur during individual matched LIS flashes, and we use the time and location of the first event rather than the nearest in time or space for the time and distance comparisons. The LIS/ENTLN matches are classified as CG if any of the subsequent ENTLN events are CG. The relative flash $\mathrm{DE}$ is the fraction of all LIS flashes in a region that are 
detected (matched) by the ENTLN. Maps of relative flash DE are computed by dividing the sum of the "matched" LIS flashes (i.e., those seen by the ENTLN) by the sum of "all" LIS flashes within $2^{\circ} \times 2^{\circ}$ grid cells. Although important insights can be gained by examining the fraction of ENTLN flashes seen by the LIS, the present study does not investigate this reverse performance metric. The present study also does not directly measure how well the ENTLN observes the propagation and spatial extent of flashes, only the efficiency at which the ENTLN detects LIS flashes (i.e., not LIS groups or events).

Data from the NLDN are incorporated to better characterize flash type (IC versus CG) to investigate the LIS characteristics of IC and CG flashes. Identical methods were employed to compare the NLDN and LIS observations within $200 \mathrm{~km}$ of the CONUS. Following this comparison, LIS flashes were subset into six categories based on 1) their ENTLN IC/CG classification and 2) whether they were observed by each network. Although some weak +CG NLDN reports likely are misclassified as IC flashes (Cummins et al. 1998), this study defines all NLDN flashes as CG. Confirmed $C G$ flashes were defined as CG by both the ENTLN and NLDN; ambiguous IC flashes were defined as IC by the ENTLN but CG by the NLDN; ambiguous $C G$ flashes were defined as CG by the ENTLN but were not observed by the NLDN; confirmed IC flashes were defined as IC by the ENTLN but were not observed by the NLDN; unmatched were observed by neither network; and only NLDN were observed by the NLDN but not the ENTLN. This analysis provides important insights into the LIS characteristics of IC and CG flashes, as well as the ambiguity of flash classification in both datasets.

\section{Results}

ENTLN performance improved between 2011 and 2013 (Table 1). Within the Western Hemisphere (between $38^{\circ} \mathrm{N}$ and $38^{\circ} \mathrm{S}$ ), the relative flash $\mathrm{DE}$ increased from $21.6 \%$ during 2011 to $31.4 \%$ during 2013 , with improving performance evident in each of the geographical subdomains. The best regional performance is over the southern half of the CONUS (south of $38^{\circ} \mathrm{N}$ ), where the ENTLN detected $62.4 \%$, $74.4 \%$, and $79.7 \%$ of the LIS flashes during 2011, 2012, and 2013, respectively. Thompson et al. (2014) reported coincident percentages (CPs; similar to relative DE) between LIS groups and ENTLN events of $28.5 \%$ and $63.3 \%$ over their Western Hemisphere and North American domains (1 January 2010-30 June 2011), respectively. Within the overall improvement, spatial and temporal variability exists in the relative DE distributions.

Table 1. Relative flash detection efficiency (DE) in the Western Hemisphere (between $38^{\circ} \mathrm{N}$ and $38^{\circ} \mathrm{S}$; both land and oceans), the contiguous United States (CONUS; south of $38^{\circ} \mathrm{N}$ within $200 \mathrm{~km}$ of shore), North America, South America, and over the Oceans during 2011, 2012, 2013, and 2011-13. North America includes only flashes over the land masses of the CONUS, Mexico, Central America, and the Caribbean Islands (i.e., no flashes over the oceans), and South America also considers only flashes over land.

\begin{tabular}{|l|c|c|c|c|}
\hline & $\mathbf{2 0 1 1}$ & $\mathbf{2 0 1 2}$ & $\mathbf{2 0 1 3}$ & $\mathbf{2 0 1 1 - 1 3}$ \\
\hline W. Hemisphere & $21.6 \%$ & $28.0 \%$ & $31.4 \%$ & $27.0 \%$ \\
\hline CONUS & $62.4 \%$ & $74.4 \%$ & $79.7 \%$ & $71.9 \%$ \\
\hline N. America & $50.3 \%$ & $60.0 \%$ & $67.4 \%$ & $59.0 \%$ \\
\hline S. America & $5.4 \%$ & $11.3 \%$ & $11.5 \%$ & $9.6 \%$ \\
\hline Oceans & $25.4 \%$ & $35.7 \%$ & $41.2 \%$ & $34.2 \%$ \\
\hline
\end{tabular}

Figure 1 illustrates the improving performance quantified in Table 1. The most notable spatial feature is the expansion of the region surrounding the CONUS with relative DE $>50 \%$. The improved performance likely reflects the implementation of new waveform processing algorithms, the addition of sensors, and the incorporation of waveforms from the WWLLN during December 2011. The WWLLN performs best over the oceans (relative to the LIS; Rudlosky and Shea 2013), so its incorporation contributes to the improved performance over the oceans between 2011 (Fig. 1a) and 2012-13 (Figs. 1b and 1c). Thompson et al. (2014) reported CPs of 3.0\% and $2.5 \%$ within their Atlantic and Pacific Ocean subdomains, respectively, which excluded large areas surrounding North and South America. Between 2011 and 2013, the relative DE over the oceans improved from $25.4 \%$ to $41.2 \%$ (Table 1). Performance also improved in West Africa (Fig. 1c) as a result of the deployment of new ENTLN sensors in Guinea. Figure 1a matches well with Fig. 5 in Thompson et al. (2014), revealing similar spatial patterns, especially surrounding the CONUS.

Examining Table 1 alongside Fig. 1 shows that the average regional values disguise important spatial distributions. For example, the ENTLN detected 9.6\% of the LIS flashes in South America (north of $38^{\circ} \mathrm{S}$ ), but had a local maximum in southeastern Brazil $(>20 \%)$ with poorer performance outside this region $(<10 \%)$. This local maximum was most pronounced during 2012. This captures the initial deployment of the Earth Networks upgrade to the BrazilDat lightning detection network, which performed best while extra 


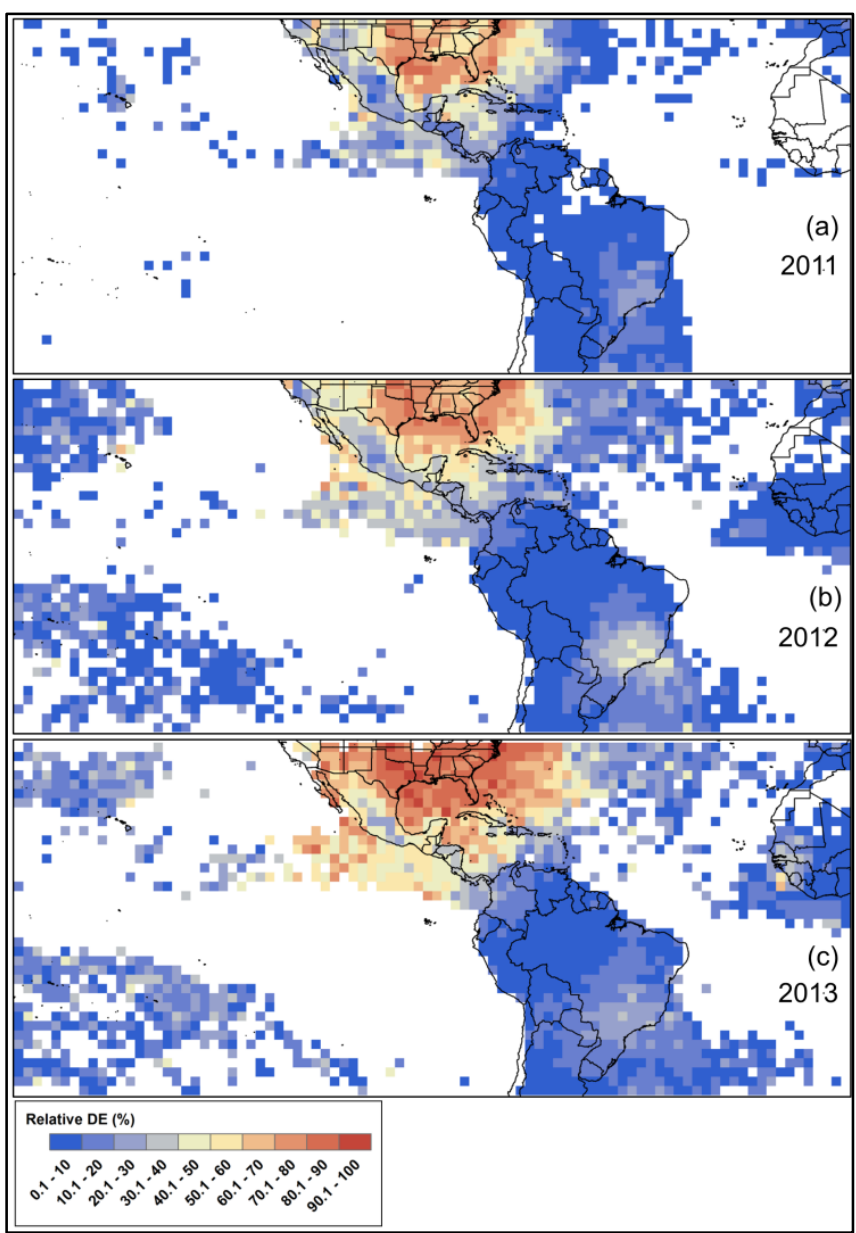

Figure 1. Spatial distributions of ENTLN relative flash detection efficiency (DE) during 2011 (panel a), 2012 (panel b), and 2013 (panel c). The relative flash DE is computed by dividing the sum of the "matched" LIS flashes by the sum of "all" LIS flashes within $2^{\circ} \times 2^{\circ}$ grid cells. White areas indicate grid cells with fewer than 15 LIS flashes. Click image for an external version; this applies to all figures hereafter.

sensors were deployed for the 2012 CHUVA field campaign (Machado et al. 2014). These distributions illustrate the importance of sensor density for providing total lightning coverage.

Both the regional averages (Table 1) and spatial plots (Fig. 1) disguise temporal variability. Figure 2 illustrates the daily ENTLN relative flash DE for (a) the Western Hemisphere and (b) North America (i.e., includes land masses of the CONUS, Mexico, Central America, and the Caribbean). The daily relative flash DE generally exceeds $15 \%$ in the Western Hemisphere and $50 \%$ in North America, but large day-to-day variability is evident (blue lines; Fig. 2). The rather large day-to-day variability also was shown by Thompson et al. (2014), and may result from the limited sampling provided by the LIS, the lightning

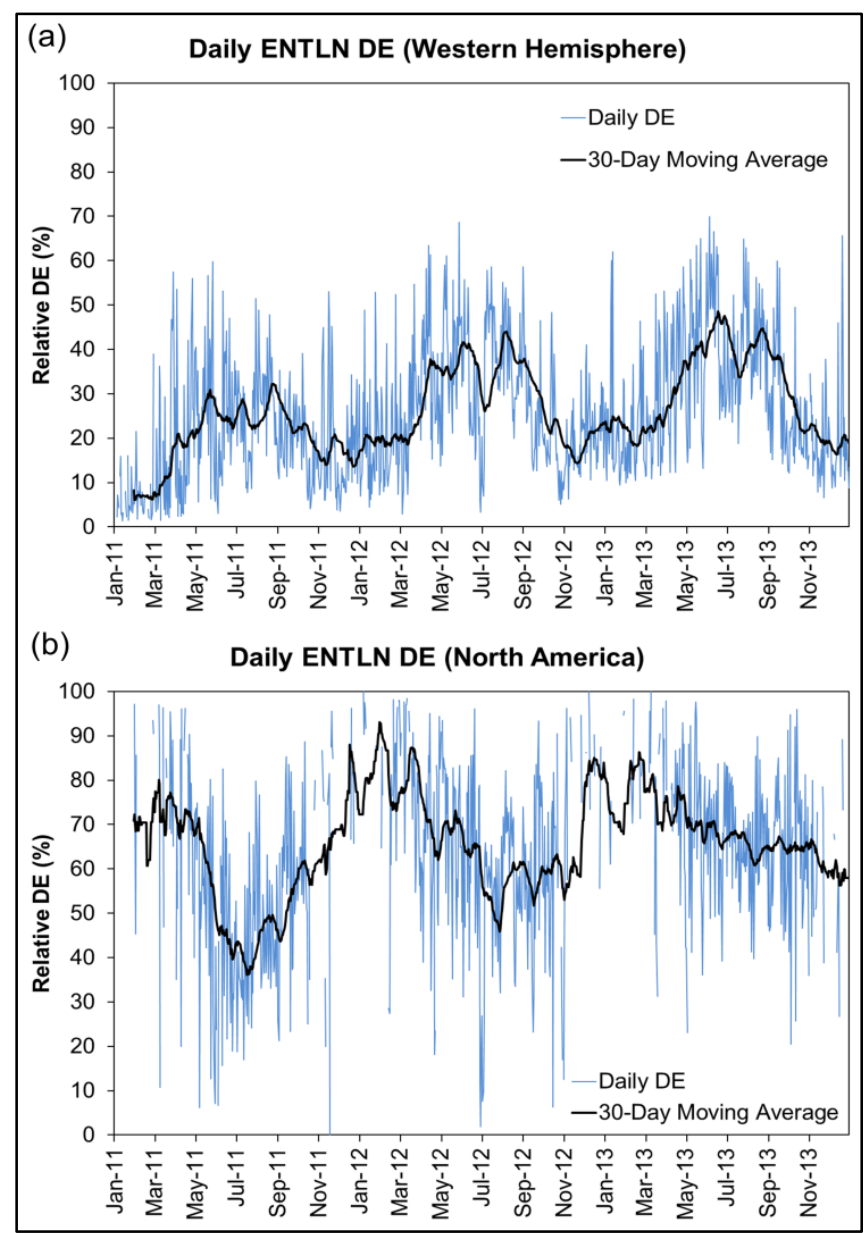

Figure 2. Average daily ENTLN relative flash DE (blue line) for (a) the Western Hemisphere between $38^{\circ} \mathrm{N}$ and $38^{\circ} \mathrm{S}$ and (b) North America (includes land masses of the southern CONUS, Mexico, Central America, and the Caribbean Islands). The black lines represent 30-day moving averages, and days with < 15 LIS flashes are omitted (only occurs in panel b).

properties, and/or the ENTLN performance (i.e., influenced by sensor spacing, sensor dropouts, ambient noise, time of day, and ground conductivity). For example, the daily $\mathrm{DE}$ values will be reduced if the LIS only observes flashes where the ENTLN has fewer sensors (i.e., less sensitivity). Both meteorology and technology greatly influence these distributions, so future work should continually evaluate and understand the ENTLN performance.

The location and timing differences (i.e., offsets) between matched LIS flashes and ENTLN events provide additional performance metrics. LIS flashes are defined by their initiation time and radianceweighted centroid. For LIS flashes that are matched with multiple ENTLN events, we use the time and location of the first ENTLN event rather than that nearest to the LIS in space or time. Table 2 reveals that 
Table 2. The average distance and time offsets ( \pm standard deviations) between matched ENTLN events and LIS flashes; the average number of ENTLN events per matched LIS flash; the fraction of matched LIS flashes that have only a single ENTLN event; and the fraction of matched LIS flashes that are defined as cloud-to-ground (CG) and intra-cloud (IC) by the ENTLN. The first four columns are for the entire Western Hemisphere domain and the final column is for CONUS (within $200 \mathrm{~km}$ ) during 2013.

\begin{tabular}{|l|c|c|c|c|c|}
\hline & $\mathbf{2 0 1 1}$ & $\mathbf{2 0 1 2}$ & $\mathbf{2 0 1 3}$ & $\mathbf{2 0 1 1}-\mathbf{1 3}$ & CONUS 2013 \\
\hline Distance Offset (km) & $10.7 \pm 6.9$ & $10.8 \pm 7.1$ & $10.8 \pm 7.0$ & $10.8 \pm 7.0$ & $10.0 \pm 6.5$ \\
\hline Time Offset (ms) & $27.9 \pm 166.8$ & $25.2 \pm 166.9$ & $22.7 \pm 162.1$ & $25.0 \pm 165.1$ & $14.5 \pm 145.3$ \\
\hline Average Events & 2.45 & 2.63 & 2.81 & 2.65 & 3.53 \\
\hline Single Event Fraction & $47.1 \%$ & $46.3 \%$ & $43.3 \%$ & $45.4 \%$ & $29.4 \%$ \\
\hline ENTLN CG Fraction & $45.5 \%$ & $55.8 \%$ & $49.3 \%$ & $51.3 \%$ & $28.9 \%$ \\
\hline ENTLN IC Fraction & $54.5 \%$ & $44.2 \%$ & $50.7 \%$ & $48.7 \%$ & \\
\hline Matched Flash Count & 123116 & 181040 & 180637 & 484793 & 109877 \\
\hline
\end{tabular}

the average distance (timing) offset between matched ENTLN and LIS locations is $10.8 \mathrm{~km}(+25.0 \mathrm{~ms})$. Although the average timing offset is positive (i.e., the ENTLN is $25 \mathrm{~ms}$ after the first LIS group), the ENTLN reports its first event before $48.6 \%$ of the LIS flashes begin, $38.5 \%$ during/after an LIS flash, and $12.9 \%$ coincident with the beginning of an LIS flash (not shown). The small average distance offset (10.8 $\mathrm{km})$ reflects our observation that discrete ENTLN events often cluster very near the radiance-weighted LIS centroid, which represents an often much larger LIS footprint (spatial extent). While the ENTLN exhibits strong performance in terms of relative flash $\mathrm{DE}$, the degree to which the network observes the propagation and spatial extent of flashes remains to be determined. Because these networks detect lightning differently (i.e., optical emissions versus electromagnetic pulses), the close proximity of matched flashes is important for GLM risk-reduction activities that seek to blend satellite- and ground-based lightning observations.

Table 2 also reveals that multiple ENTLN events occur during most matched LIS flashes. A single event occurred during $45.4 \%$ of matches (Table 2), and the ENTLN detected an average 2.65 events for each matched LIS flash. This is much smaller than the average 10+ LIS groups (50+ events) for each matched LIS flash (Table 3). The ENTLN classified 51.3\% (48.7\%) of all matched LIS flashes as CG (IC), but ambiguity remains in the accuracy of this IC/CG classification. Within $200 \mathrm{~km}$ of the CONUS, an average of 3.53 ENTLN events occurred during each matched LIS flash, and the ENTLN classified 28.9\% (71.1\%) of the matches as CG (IC).

Data from the NLDN help better characterize flash type (IC versus CG), allowing for proper investigation of the LIS characteristics of IC and CG flashes. Recall the reported tendency for the ENTLN to misclassify subsequent (weak) CG return strokes as IC flashes (Mallick et al. 2013, 2014) and for the NLDN to misclassify some IC discharges as low-amplitude +CG reports (Cummins et al. 1998). LIS flashes were subset into six categories based on their ENTLN IC/CG classification and whether they were observed by each network. Overall, $17.0 \%$ of the LIS flashes within 200 $\mathrm{km}$ of CONUS were classified as confirmed $C G$ (defined as CG by both the ENTLN and NLDN), $20.7 \%$ were ambiguous IC (defined as IC by the ENTLN but CG by the NLDN), $8.1 \%$ were ambiguous $C G$ (defined as CG by the ENTLN but not observed by the NLDN), $26.1 \%$ were confirmed IC (defined as IC by the ENTLN and not observed by the NLDN), $24.0 \%$ were unmatched (observed by neither network), and $4.1 \%$ were only NLDN (observed by the NLDN but not the ENTLN).

Table 3 reveals that the ENTLN detected the most intense LIS flashes, and the LIS characteristics also indicate that CG flashes transferred more charge than IC flashes. Recall that the LIS characteristics indicate the intensity or amount of charge transferred by individual flashes. The unmatched flashes are smallest $\left(197.3 \mathrm{~km}^{2}\right)$ and have the shortest average duration $(5.1 \mathrm{~ms})$, indicating that they are weakest (i.e., transfer the least charge). The confirmed $C G$ flashes are largest $\left(428.4 \mathrm{~km}^{2}\right)$ and last longest $(24.0 \mathrm{~ms})$, whereas only the unmatched flashes are smaller and shorter than the confirmed IC flashes. If the unmatched LIS flashes are assumed to be IC, then combining the confirmed $C G$ $(17.0 \%)$ with the only NLDN (4.1\%) suggests that roughly 1-in-5 LIS flashes are CG (excluding the ambiguous flashes).

This comparison provides important insights into the ambiguity of flash classification in both datasets. As expected, the LIS characteristics of the ambiguous $I C$ and ambiguous $C G$ flashes are between the confirmed $\mathrm{CG}$ and confirmed IC values (Table 3 ). Figure 3 reveals that $67.2 \%$ of the ambiguous IC flashes have NLDN-estimated peak currents in the ambiguous weak $+\mathrm{CG}$ range (0-15 kA). Thus, the ambiguous IC flashes 
Table 3. The LIS flashes are subset into six categories based on 1) their ENTLN IC/CG classification and 2) whether they are observed by the ENTLN and NLDN. Confirmed CG flashes are defined as CG by both the ENTLN and NLDN; ambiguous IC flashes are defined as IC by the ENTLN but CG by the NLDN; ambiguous CG are defined as CG by the ENTLN but are not observed by the NLDN; confirmed IC are defined as IC by the ENTLN and not observed by the NLDN; unmatched are observed by neither network; and only NLDN are observed by the NLDN but not the ENTLN. The table also includes the average characteristics ( \pm standard deviations) of LIS flashes for each category (in the Western Hemisphere during 2011-13). The MNEG is the maximum number of events per group and MGA is the maximum group area.

\begin{tabular}{|l|c|c|c|c|c|c|}
\hline & Confirmed CG & Ambiguous IC & Ambiguous CG & Confirmed IC & Unmatched & Only NLDN \\
\hline & $\begin{array}{c}\text { ENTLN CG } \\
\text { NLDN CG }\end{array}$ & $\begin{array}{c}\text { ENTLN IC } \\
\text { NLDN CG }\end{array}$ & $\begin{array}{c}\text { ENTLN CG } \\
\text { No NLDN }\end{array}$ & $\begin{array}{c}\text { ENTLN IC } \\
\text { No NLDN }\end{array}$ & $\begin{array}{c}\text { No ENTLN } \\
\text { No NLDN }\end{array}$ & $\begin{array}{c}\text { No ENTLN } \\
\text { NLDN CG }\end{array}$ \\
\hline 2011 (122707) & $16299(13.3 \%)$ & $19473(15.9 \%)$ & $8129(6.6 \%)$ & $32706(26.7 \%)$ & $37802(30.8 \%)$ & $8298(6.8 \%)$ \\
\hline 2012 (118958) & $22927(19.3 \%)$ & $20680(17.4 \%)$ & $12384(10.4 \%)$ & $32563(27.4 \%)$ & $27295(22.9 \%)$ & $3109(2.6 \%)$ \\
\hline 2013 (109877) & $20468(18.6 \%)$ & $32682(29.7 \%)$ & $8026(7.3 \%)$ & $26379(24.0 \%)$ & $19185(17.5 \%)$ & $3137(2.9 \%)$ \\
\hline 3YRS (351542) & $59694(17.0 \%)$ & $72835(20.7 \%)$ & $28539(8.1 \%)$ & $91648(26.1 \%)$ & $84282(24.0 \%)$ & $14544(4.1 \%)$ \\
\hline & & & & & & \\
\hline Groups (count) & $15.4 \pm 19.3$ & $15.6 \pm 17.8$ & $14.9 \pm 16.8$ & $11.9 \pm 13.6$ & $8.6 \pm 10.4$ & $11.7 \pm 13.9$ \\
\hline Events (count) & $77.6 \pm 109.5$ & $61.7 \pm 95.2$ & $58.6 \pm 87.3$ & $43.1 \pm 69.8$ & $30.4 \pm 55.2$ & $51.4 \pm 82.0$ \\
\hline Duration (ms) & $24.0 \pm 412.9$ & $21.8 \pm 407.5$ & $18.3 \pm 392.3$ & $11.8 \pm 354.2$ & $5.1 \pm 287.4$ & $12.2 \pm 346.1$ \\
\hline Area (km $)$ & $428.4 \pm 382.1$ & $293.2 \pm 265.3$ & $288.8 \pm 246.3$ & $230.2 \pm 192.8$ & $197.3 \pm 193.2$ & $316.0 \pm 308.9$ \\
\hline MNEG (count) & $14.9 \pm 15.2$ & $9.8 \pm 10.0$ & $9.6 \pm 9.2$ & $7.7 \pm 7.1$ & $6.8 \pm 7.1$ & $11.0 \pm 11.9$ \\
\hline MGA (km $\left.{ }^{2}\right)$ & $378.4 \pm 358.7$ & $251.9 \pm 239.7$ & $249.3 \pm 222.9$ & $200.4 \pm 170.5$ & $176.1 \pm 174.5$ & $282.9 \pm 291.2$ \\
\hline
\end{tabular}

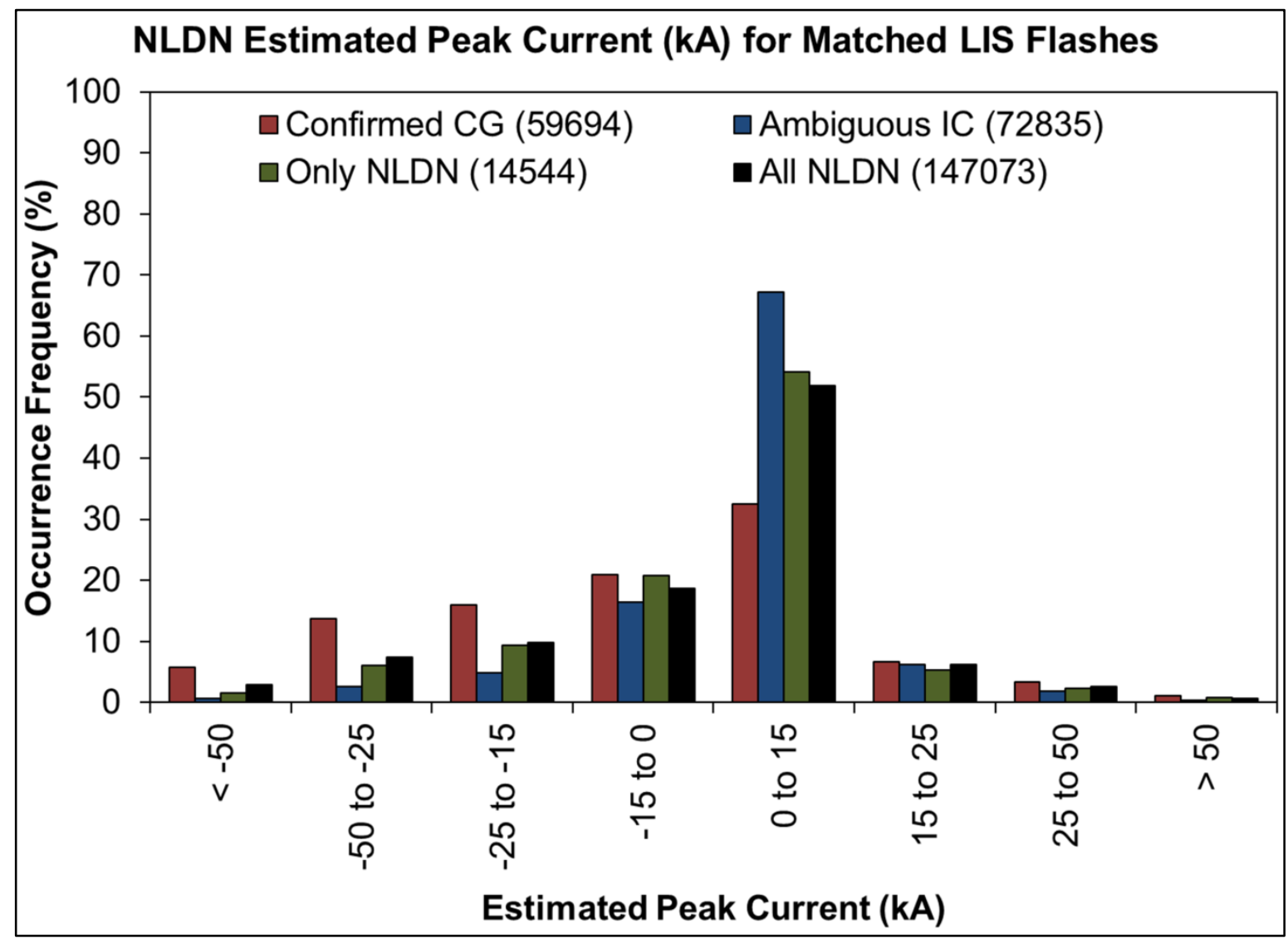

Figure 3. Estimated peak current reported by the NLDN for matched LIS flashes. Confirmed CG flashes are defined as CG by both the ENTLN and NLDN, ambiguous IC flashes are defined as IC by the ENTLN but CG by the NLDN, only $N L D N$ are observed by the NLDN but not the ENTLN, and all NLDN is all LIS flashes observed by the NLDN. NLDN flashes with peak current between 0 and $15 \mathrm{kA}$ typically are discarded as ambiguous or misclassified weak positive cloudto-ground flashes (many are actually intra-cloud). 
appear to be mostly IC, with some true CG flashes. Many of the ambiguous $C G$ flashes occurred over the Gulf Stream (150-200 km off shore; not shown), which helps explain many of the ENTLN CG flashes that were missed by the NLDN. However, ambiguous $C G$ flashes occurred elsewhere in the CONUS, which will require further investigation. These findings illustrate the challenge of classifying IC and CG flashes, and highlight the need for more research into these ambiguous events.

As the application of lightning data continues to expand, it becomes increasingly important to properly identify and characterize all lightning flashes. Many operational users must know whether flashes strike the ground, and if so, their intensity, polarity, multiplicity, and continuing current. Koshak (2010) introduced the maximum number of events per group (MNEG) and maximum group area (MGA) as potential return stroke identifiers (i.e., CG versus IC), and showed that for large samples these variables can be used to estimate the IC to CG ratio. Our analysis supports the use of these metrics by illustrating that the MNEG and MGA are much larger for confirmed $C G$ flashes (14.9 and $378.4 \mathrm{~km}^{2}$, respectively) than for confirmed IC flashes (7.7 and $200.4 \mathrm{~km}^{2}$, respectively). These findings should help guide the development of operational applications that leverage both ground- and spacebased lightning observations to best characterize lightning flashes and their potential impact.

\section{Summary}

This study compared three years (2011-13) of data from the ENTLN and the TRMM LIS. The fraction of LIS flashes detected by the ENTLN was reported to improve our understanding of the ENTLN detection capabilities and enhance its use in weather research and operations.

ENTLN performance improved between 2011 and 2013. Within the Western Hemisphere $\left(38^{\circ} \mathrm{N}\right.$ to $\left.38^{\circ} \mathrm{S}\right)$, the relative flash DE increased from $21.6 \%$ during 2011 to $31.4 \%$ during 2013. Improved performance was evident in each of the geographical subdomains. The best regional performance occurred over the southern CONUS (south of $38^{\circ} \mathrm{N}$ ), where the ENTLN detected $71.9 \%$ of LIS flashes during 2011-13.

The most notable spatial feature was the expansion of the region surrounding the CONUS with a relative $\mathrm{DE}>50 \%$. The relative DE over the oceans also improved from $25.4 \%$ to $41.2 \%$ between 2011 and 2013. Performance improved in West Africa, and exhibited a local maximum in southeastern Brazil during 2012. These findings illustrate the importance of sensor density for providing total lightning coverage. The daily relative flash DE generally exceeded $15 \%(50 \%)$ in the Western Hemisphere (North America), but large day-to-day variability was evident. Both meteorology and technology greatly influence these distributions, so future work must continually evaluate and understand the ENTLN performance.

The average distance (timing) offset between matched LIS flashes and ENTLN events was $10.8 \mathrm{~km}$ $(+25.0 \mathrm{~ms})$. Although the average timing offset was positive, the ENTLN reported its first event before $48.6 \%$ of the LIS flashes began. The close proximity of matched flashes is important for GLM riskreduction activities that seek to blend satellite- and ground-based lightning observations.

Multiple ENTLN events occurred during most matched LIS flashes. A single event occurred during $45.4 \%$ of matches, and the ENTLN detected an average 2.65 events for each matched LIS flash. This was much smaller than the average 10+ LIS groups (50+ events) for each matched LIS flash. The ENTLN defined $51.3 \%(48.7 \%)$ of all matched LIS flashes as CG (IC), but ambiguity remains in the accuracy of this IC/CG classification. Within $200 \mathrm{~km}$ of the CONUS, an average of 3.53 ENTLN events occurred during each matched LIS flash, and the ENTLN classified $28.9 \%(71.1 \%)$ of the matches as CG (IC).

Data from the NLDN helped characterize flash type (IC versus CG), and allowed an investigation of the LIS characteristics of IC and CG flashes. This comparison also provided important insights into the ambiguity of flash classification in both datasets. LIS flashes were subset into six categories based on their ENTLN IC/CG classification and whether they were observed by each network. Overall, $17.0 \%$ of LIS flashes within $200 \mathrm{~km}$ of the CONUS were characterized as confirmed CG, $20.7 \%$ were ambiguous $I C$, $8.1 \%$ were ambiguous $C G, 26.1 \%$ were confirmed $I C$, $24.0 \%$ were unmatched, and $4.1 \%$ were only NLDN.

The ENTLN detected the most intense LIS flashes, and the LIS characteristics also indicated that CG flashes transfer more charge than IC flashes. The unmatched flashes were smallest $\left(197.3 \mathrm{~km}^{2}\right)$ and had the shortest average duration $(5.1 \mathrm{~ms})$, indicating they were weakest. The confirmed $C G$ flashes were largest $\left(428.4 \mathrm{~km}^{2}\right)$ and lasted longest $(24.0 \mathrm{~ms})$, whereas only the unmatched flashes were smaller and shorter than the confirmed IC flashes. For the ambiguous IC flashes, $67.2 \%$ had NLDN-estimated peak currents in 
the ambiguous weak $+\mathrm{CG}$ range $(0-15 \mathrm{kA})$, suggesting that this group consisted mostly of IC flashes, with some true CG flashes mixed in. The MNEG and MGA were much larger for confirmed $C G$ flashes (14.9 and $378.4 \mathrm{~km}^{2}$, respectively) than for confirmed IC flashes (7.7 and $200.4 \mathrm{~km}^{2}$, respectively).

Results suggest that the ENTLN provides the broad area coverage required for many weather research and operational applications. This study should help Earth Networks better characterize their network performance, and provide researchers and forecasters with important insights as the operational use of these data continues to grow. Future studies should seek to determine which combinations of space- and groundbased lightning observations best characterize lightning flashes and their destructive potential.

Acknowledgments. Funding for this project was provided by NOAA/NESDIS through the Center for Satellite Applications and Research (STAR) and the Cooperative Institute for Climate and Satellites-Maryland (CICS-MD). The author thanks Earth Networks, Inc., and Vaisala, for providing the lightning data used in this paper, as well as the Lightning and Atmospheric Electricity Group at NASA's Marshall Space Flight Center for their support of the TRMM/LIS archive. The insights of several anonymous reviewers helped shape this manuscript, and were much appreciated. The author specifically thanks Stan Heckman, Chris Sloop, and Alex Fierro for their insights. The contents of this paper are solely the opinions of the author and do not constitute a statement of policy, decision, or position on behalf of NOAA or the United States government.

\section{REFERENCES}

Biagi, C. J., K. L. Cummins, K. E. Kehoe, and E. P. Krider, 2007: National Lightning Detection Network (NLDN) performance in southern Arizona, Texas, and Oklahoma in 2003-2004. J. Geophys. Res., 112, D05208, CrossRef.

Boccippio, D. J., W. J. Koshak, and R. J. Blakeslee, 2002: Performance assessment of the Optical Transient Detector and Lightning Imaging Sensor. Part I: Predicted diurnal variability. J. Atmos. Oceanic Technol., 19, 1318-1332, CrossRef.

Cecil, D. J., D. E. Buechler, and R. J. Blakeslee, 2012: Gridded lightning climatology from TRMM-LIS and OTD: Dataset description. Atmos. Res., 135-136, 404414, Cross Ref.

Christian, H. J., R. J. Blakeslee, and S. J. Goodman, 1992: Lightning Imaging Sensor (LIS) for the Earth Observing System. NASA TM-4350, 44 pp. [Available online at ntrs.nasa.gov/archive/nasa/casi.ntrs.nasa.gov/ 19920010794.pdf.]

Christian, H. J., and Coauthors, 1999: The lightning imaging sensor. NASA conference publication, 746749. [Available online at thunder.msfc.nasa.gov/ bookshelf/pubs/LIS_ICAE99_Print.pdf.]

Christian, H. J., and Coauthors, 2003: Global frequency and distribution of lightning as observed from space by the Optical Transient Detector. J. Geophys. Res., 108, 4005, CrossRef.

Cummins, K. L., and M. J. Murphy, 2009: An overview of lightning locating systems: History, techniques, and data uses, with an in-depth look at the U.S. NLDN. IEEE Trans. on Electromagn. Compat., 51, 499-518, CrossRef.

, E. A. Bardo, W. L. Hiscox, R. B. Pyle, and A.

E. Pifer, 1998: A combined TOA/MDF technology upgrade of the U.S. National Lightning Detection Network. J. Geophys. Res., 103, 9035-9044, CrossRef. , J. A. Cramer, C. J. Biagi, E. P. Krider, J. Jerauld, M. A. Uman, and V. A. Rakov, 2006: The U.S. National Lightning Detection Network: Post-upgrade status. Preprints, Second Conf. on the Meteorological Applications of Lightning Data, Atlanta, GA, Amer. Meteor. Soc., 6.1. [Available online at ams.confex.com/ ams/pdfpapers/105142.pdf.]

DeMaria, M., R. T. DeMaria, J. A. Knaff, and D. Molenar, 2012: Tropical cyclone lightning and rapid intensity change. Mon. Wea. Rev., 140, 1828-1842, CrossRef.

Fierro, A. O., E. R. Mansell, C. L. Ziegler, D. R. MacGorman, 2012: Application of a lightning data assimilation technique in the WRF-ARW model at cloud-resolving scales for the tornado outbreak of 24 May 2011. Mon. Wea. Rev., 140, 2609-2627, CrossRef.

Gatlin, P. N., and S. J. Goodman, 2010: A total lightning trending algorithm to identify severe thunderstorms. $J$. Atmos. Oceanic Technol., 27, 3-22, CrossRef.

Goodman S. J., and Coauthors, 2013: The GOES-R Geostationary Lightning Mapper (GLM). Atmos. Res., 125-126, 34-49, CrossRef.

Koshak, W. J., 2010: Optical characteristics of OTD flashes and the implications for flash-type discrimination. $J$. Atmos. Oceanic Technol., 27, 1822-1838, CrossRef.

Liu, C., and S. Heckman, 2012: Total lightning data and real-time severe storm prediction. Conf. Meteor. Environ. Instruments and Methods of Observation Management Group. Brussels, Belgium, World Meteorological Organization, P5 (10).

Mach, D. M., H. J. Christian, R. J. Blakeslee, D. J. Boccipio, S. J. Goodman, and W. L. Boeck, 2007: Performance assessment of the Optical Transient Detector and Lightning Imaging Sensor. J. Geophys. Res., 112, D09210, CrossRef.

Machado, L. A. T., and Coauthors, 2014: The CHUVA Project: How does convection vary across Brazil? Bull. Amer. Meteor. Soc., 95, 1365-1380, CrossRef. 
Mallick, S., V. A. Rakov, J. D. Hill, W. R. Gamerota, M. A. Uman, S. Heckman, C. D. Sloop, and C. Liu, 2013: Calibration of the ENTLN against rocket-triggered lightning data. Proc. 2013 Int. Symp. on Light. Prot. (XII SIPDA), Belo Horizonte, Brazil, 39-46, CrossRef. , and Coauthors, 2014: An update on testing the performance characteristics of the ENTLN. Preprints, 15th Int. Conf. Atmos. Electricity, Norman, OK, 11 pp. [Available online at www.nssl.noaa.gov/users/mansell/ icae2014/preprints/Mallick_168.pdf.]

Rudlosky, S. D., and D. T. Shea, 2013: Evaluating WWLLN performance relative to TRMM/LIS. Geophy. Res. Lett., 40, 2344-2348, $\underline{\text { CrossRef. }}$

Schultz, C. J., W. A. Petersen, and L. D. Carey, 2009: Preliminary development and evaluation of lightning jump algorithms for the real-time detection of severe weather. J. Appl. Meteor. Climatol., 48, 2543-2563, CrossRef.

, and __, 2011: Lightning and severe weather: A comparison between total and cloud-to-ground lightning trends. Wea. Forecasting, 26, 744-755, CrossRef.
Simpson, J., R. F. Adler, and G. R. North, 1988: A proposed Tropical Rainfall Measuring Mission (TRMM) satellite. Bull. Amer. Meteor. Soc., 69, 278-295, CrossRef.

Thompson, K. B., M. G. Bateman, and L. D. Carey, 2014: A comparison of two ground-based lightning detection networks against the satellite-based Lightning Imaging Sensor (LIS). J. Atmos. Oceanic Technol., 31, 21912205, CrossRef.

Williams, E. R., and Coauthors, 1999: The behavior of total lightning activity in severe Florida thunderstorms. Atmos. Res., 51, 245-265, CrossRef.

$\mathrm{Xu}, \mathrm{W} ., \mathrm{R} . \mathrm{F}$. Adler, and N-Y. Wang, 2013: Improving geostationary satellite rainfall estimates using lightning observations: Underlying lightning-rainfall-cloud relationships. J. Appl. Meteor. Climatol., 52, 213-229, CrossRef. , and 2014: Combining satellite infrared and lightning information to estimate warm-season convective and stratiform rainfall. J. Appl. Meteor. Climatol., 53, 180-199, CrossRef. 